DOI: https://doi.org/10.36910/6775-2524-0560-2021-43-20

УДК 681.121.89.082.4

Роман Віталій Іванович, доцент, к.т.н.

https://orcid.org/0000-0002-8546-6752

Іжик Ангеліна Борисівна, студентка

Національний університет «Львівська політехніка», м. Львів, Україна

\title{
АНАЛІТИЧНІ ЗАЛЕЖНОСТІ РОЗРАХУНКУ КООРДИНАТ РОЗТАШУВАННЯ ТА ВАГОВИХ КОЕФІЦІЕНТІВ АКУСТИЧНИХ КАНАЛІВ УЛЬТРАЗВУКОВИХ ВИТРАТОМІРІВ
}

Роман В.І., Іжик А.Б. Аналітичні залежності розрахунку координат розташування та вагових коефіціснтів акустичних каналів ультразвукових витратомірів. На базі числового методу інтегрування Гауса-Якобі розроблено аналітичні залежності розрахунку координат розташування та вагових коефіцієнтів акустичних каналів для дво-, трьох- та чотириканальних хордових ультразвукових витратомірів.

Ключові слова: ультразвуковий витратомір, акустичний канал, числовий метод інтегрування Гауса, поліном Якобі, апроксимація.

Роман В.И., Ижик А.Б. Аналитические зависимости расчета координат местоположения и весовых коэффициентов акустических каналов ультразвуковых расходомеров. На базе численного метода интегрирования Гаусса-Якоби разработаны аналитические зависимости расчета координат местоположения и весовых коэффициентов акустических каналов для двух-, трех- и четырехканальных хордовых ультразвуковых расходомеров.

Ключевые слова: ультразвуковой расходомер, акустический канал, численный метод интегрирования Гаусса, полином Якоби, аппроксимация.

Roman V.I., Izhik A.B. Analytical dependences of calculation of location coordinates and weight coefficients of acoustic paths of ultrasonic flowmeters. On the basis of Gauss-Jacobi numerical integration methods developed analytical calculation depending on location coordinates and weighting coefficients acoustic paths of two-, three- and four-path chordal ultrasonic flow meters.

Keywords: ultrasonic flowmeter, acoustic path, Gauss numerical integration method, Jacobi polynomial, approximation.

Постановка наукової проблеми. Принцип роботи багатоканальних ультразвукових витратомірів (УЗВ) полягає у вимірюванні швидкості потоку не в поперечному перерізі вимірювального трубопроводу (ВТ), як того вимагає швидкісний метод вимірювання витрати, а вздовж акустичних каналів (АК) витратоміра [1]. При цьому, існує два способи підсумовування значень цих усереднених швидкостей [1]: 3 постійними або змінними ваговими коефіцієнтами. Зокрема, постійні вагові коефіцієнти визначаються на підставі відомих числових методів інтегрування (до прикладу, метод Гауса-Якобі $[2,3]$ ), а змінні - за виміряними параметрами потоку (наприклад, швидкістю потоку) [1]. Також, числові методи інтегрування (ЧМІ) використовуються при розрахунку координат розташування АК УЗВ. Тому, під час наукових досліджень, проектуванні нових або удосконаленні існуючих багатоканальних УЗВ виникає потреба використання ЧМІ. Оскільки алгоритм роботи ЧМІ для визначення вагових коефіцієнтів та координат розташування АК УЗВ є досить складними та ітераційними [2, 3], в даній роботі поставлено за мету розробити поліноміальні залежності, які б зв'язували значення вагових коефіцієнтів та координат розташування АК УЗВ зі степенем вагової функції ЧМІ Гауса-Якобі.

Аналіз досліджень. Застосування ЧМІ для розрахунку витрати багатоканальних УЗВ за швидкостями вздовж їх АК вперше задокументовано патентом компанії Westinghouse в 1965 році. Перший комерційний УЗВ природного газу, який використовував метод Гаусових квадратур, запатентовано компанії British Gas Corporation в 1986 році. Застосування ЧМІ для задач багатоканальної ультразвукової витратометрії досліджено і представлено в багатьох наукових працях [2-5], зокрема у звітах Американської газової асоціації [6] та Європейської групи по дослідженню газу [7]. До слова, в [7] чітко рекомендується застосовувати ЧМІ Гауса-Якобі або спеціально розроблені методи на його базі. Вклад в дослідження ЧМІ для вимірювання витрати акустичним методом внесли Voser, Tresch, Gruber та Staubli. В своїх працях вони досліджували ЧМІ ГаусаЛежандра і Гауса-Якобі, що занесені в стандарти IEC 41 та ASME PTC18-2002, як ЧМI при вимірювання витрати води акустичним методом (acoustic discharge measurement, ADM). Модифікувавши метод Гауса-Якобі, Voser розробив новий метод для визначення координат розташування АК та їх вагових коефіцієнтів, який покращив результат попереднього методу на $0,1 \ldots 0,2 \%$ [3]. В подальшому, Tresch, Gruber та Staubli також запропонували удосконалювати ЧМІ Гауса-Якобі шляхом модифікації показника степеня його вагової функції [2].

В результаті виконаного огляду можна з впевненістю сказати, що ЧМІ Гауса-Якобі є основним (C) Роман В.I., Іжик А.Б. 
методом при визначенні координат розташування та вагових коефіцієнтів АК УЗВ. Проте, серед провідних науковців і дотепер не існує єдиного переконання який ЧМІ використовувати при проектуванні УЗВ. Так, наприклад, фірма Daniel використовує метод Гауса-Якобі, фірма RMG використовує метод Гауса-Чебишева, фірма Caldon - метод Гауса-Лежандра. Також, у наведених вище джерелах не розглянуто залежності вагових коефіцієнтів від координат розташування АК та не вказано, який саме ЧМІ найкраще відтворює профіль потоку та забезпечує найвищу точність інтегрування витрати. Тому, питання дослідження ЧМІ для задач багатоканальних ультразвукової витратометрії залишається відкритим. Розробка аналітичних залежностей, які зв'яжуть значення вагових коефіцієнтів та координат розташування АК УЗВ зі степенем вагової функції ЧМІ ГаусаЯкобі, дозволить проводити швидкі порівняльні дослідження різноманітних конструкцій УзВ із застосуванням комп'ютерної техніки та відомих формул профілів потоку, зокрема спотвореного (у вигляді функцій Salami).

В даній роботі частково використані результати досліджень, викладених в магістерській кваліфікаційній роботі [14] студента, науковим керівником якого був Роман В.I.

Виклад матеріалу. УЗВ у якому застосовано більше ніж один АК називають багатоканальним. В залежності від схеми просторового розташування АК, УЗВ поділяють на хордові, діаметральні або комбіновані [1]. В даній роботі досліджено найбільш розповсюджені - хордові УЗВ, у яких АК розташовані у симетричних відносно осі не діаметральних площинах (див.рис.1). Для обчислення об'ємної витрати багатоканальних хордових УЗВ $\left(q_{U S M}\right)$ може бути застосована наступна формула [2, 3]:

$$
q_{U S M}=\pi R^{2} \sum_{i=1}^{N}\left(\frac{2 \sqrt{R^{2}-x(i)^{2}}}{\pi R} w(i) u_{h}(i)\right),
$$

де $R$ - внутрішній радіус ВТ (або корпусу УЗВ); $x(i), w(i)$ - координата розташування та ваговий коефіцієнт $i$-го АК; $u_{h}(i)$ - усереднена вздовж $i$-го хордового АК швидкість потоку; $N$ - кількість АК.

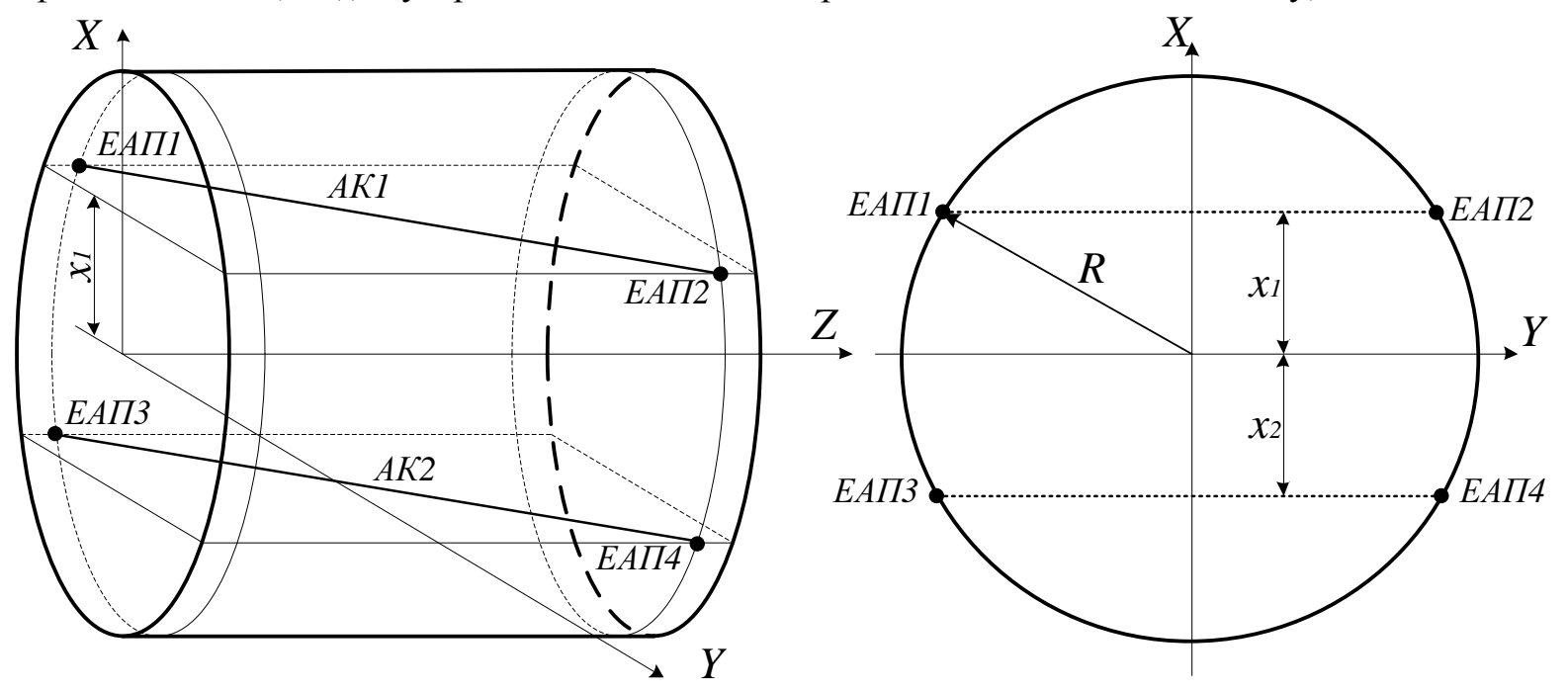

Рис. 1. Спрощена схема просторового розташування АК двоканального хордового УЗВ: ЕАП - електроакустичний перетворювач

Для реалізації формули (1) необхідно мати значення $x(i)$ та $w(i)$, а також значення середньої швидкість потоку $u_{h}(i)$ вздовж кожного хордового АК. Як було зазначено вище, для розрахунку значень $x(i)$ та $w(i)$ використовують ЧМІ.

Згідно теорії, первинно об'ємна витрата потоку через переріз ВТ круглої форми може бути описана подвійним визначеним інтегралом, де підінтегральною функцією виступає розподіл швидкості потоку в перерізі ВТ. Враховуючи, що розподіл швидкості залежить від багатьох факторів (число Рейнольдса, шорсткість внутрішньої поверхні ВТ, зовнішні сили, що діють на потік під час руху по ВТ складної конфігурації), його аналітична форма (підінтегральна функція) ускладнюється $[2,3]$.

В тих випадках, коли неможливо розрахувати визначений інтеграл за класичною формулою Ньютона-Лейбніца, зокрема із-за занадто складного вигляду первісної функції, застосовують числові методи [8-9]. Визначений інтеграл в такому випадку можна розглядати як функціонал 
$J_{1}=\int_{a}^{b} W(x) f(x) d x$, заданий на деякій множині $f \in D(J)$, де $W(x) \geq 0$ - задана вагова функція. У випадку вимірювання витрати функція $f(x)$ це аналітична форма розподілу швидкості в перерізі ВТ.

Однією із загальних ідей при побудові алгоритмів наближеного обчислення такого інтегралу $\epsilon$ наступна [8-9]: для підінтегральної функції будується деяке наближення і наближено покладають $J_{2} \approx \int_{a}^{b} W(x) f^{h}(x) d x$. Звичайно, наближення $f^{h}(x)$ має бути таким, щоб інтеграл $J_{2}$ обчислювався простіше, ніж інтеграл $J_{1}$. В математиці поширені наближення, які лінійно виражаються через функцію $f(x)$ та іiі похідні в точках із діапазону інтегрування функції. На практиці, згідно аналізу науково-технічних праць $[10,11]$, розглядаються наближення в яких використовують лише значення функції $f(x)$ і не використовуються ії похідні.

Формула для розрахунку визначеного інтеграла 3 використанням ЧМІ без застосування похідних виглядає наступним чином $J_{3} \approx \sum_{j=1}^{N t} w_{j} f\left(x_{j}\right)$, де $N t-$ число точок, в яких вираховують значення підінтегральної функції $f(x)$. Точки в яких вираховують значення підінтегральної функції $x$ називають абсцисами ЧМІ, а $w$ - вагами ЧМІ [8-11]. Практично абсцисам ЧМІ відповідають координати розташування АК УЗВ, а вагам ЧМІ відповідають вагові коефіцієнти АК, які множаться на швидкості знайдені вздовж цих каналів ультразвуковим методом. В результаті кількість абсцис $N t$ ЧМІ відповідатиме кількості АК $N$ (далі $N t$ позначатимемо як $N$ ).

Інтеграл $J_{3} \quad 3$ інтегралу $J_{2}$ можна отримати, якщо вибрати $f^{h}(x)$ у вигляді $f^{h}(x) \equiv p_{N t-1}(x ; f)=\sum_{j=1}^{N t} f\left(x_{j}\right) l_{j, N t-1}(x)$, де $p_{N t-1}(x ; f)$ - інтерполяційний поліном степеня $N t-1$ для функції $f(x)$ за вузлами $x_{j}, j=1 \ldots N t ; l_{j, N t-1}-$ фундаментальні інтерполяційні поліноми. В такому випадку $w_{j}=\int_{a}^{b} W(x) l_{j, N t-1}(x) d x[8]$.

Згідно такого підходу ЧМІ поділяються на три групи [8]: методи Ньютона-Котеса (прямокутників, трапецій, Сімпсона, трьох восьмих та інші); метод Чебишева; методи найвищого ступеня точності Гауса.

ЧМІ першої групи застосовуються для розв'язку так званої задачі Ньютона [10]: коли для заданого розташування абсцис і їх кількості, потрібно знайти найкращі значення вагів ЧМІ. Дана задача $\epsilon$ найбільш гнучкою, так як для довільного розташування абсцис дозволяє знайти оптимальне значення вагів. При цьому, при заміні підінтегральної функції на поліном нульового, першого і другого степеня отримаємо ЧМІ прямокутників, трапецій, Сімпсона відповідно. Проте, застосування цього класу ЧМІ для багатоканальних УЗВ є незручним. Це пояснюється тим, що в цих методах вимагається для абсцис використовувати фіксовані точки (крайні точки інтервалу інтегрування та його середину). Практично це недопустимо, так як розташування АК прямо на стінці ВТ $\epsilon$ технологічно неможливим. Також, ці методи згідно правила Рунге мають низький порядок точності (0 - метод правих і лівих прямокутників, 1 - метод середніх прямокутників і трапецій; 3 - метод парабол Сімпсона).

ЧМІ другої групи застосовуються для розв'язку так званої задачі Чебишева [10]: для заданих значень вагів та їх кількості знайти оптимальне значення абсцис. Зважаючи на трактування задачі реалізувати ï для багатоканального УЗВ буде складно, так як потрібно на перед знати структуру потоку яка б враховувалась певним розташуванням АК. Окрім реалізації, в роботі [11], проведено аналіз ЧМІ і показано, що метод Чебишева дає найбільшу похибку інтегрування. Відповідно застосування цього ЧМІ не розглядається в даній роботі.

ЧМІ третьої групи застосовуються для розв'язку так званої задачі Гауса [10]: знайти оптимальні значення абсцис і відповідні їм значень вагів. ЧМІ Гауса із-за своїх властивостей дозволяють визначити абсциси і ваги таким чином, щоб отримати формулу ЧМІ якомога більшого порядку точності на відміну від обмежених у цьому попередніх методів. В роботі [11], методи Гауса дають найменшу похибку інтегрування. Відповідно застосування цього ЧМІ $є$ актуальним i доречним, щоб бути розглянутим в даній роботі.

Порядок точності ЧМІ Гауса складає $2 N-1$, такий результат досягається використанням (c) Роман B.I., Іжик А.Б. 
ортогональних поліномів в якості вагових функцій [13]. В залежності від поліномів, які використовуються в формулі ЧМІ Гауса, існує ряд різновидів даного методу. Серед найбільш застосовуваних ЧМІ Гауса можна назвати метод Гауса-Якобі. Його формула для відносного інтервалу інтегрування $x \in[-1 ; 1]$ із використанням ортогонального ультрасферичного полінома Якобі виглядає наступним чином $\int_{-1}^{+1} W(x) f(x) d x=\sum_{j=1}^{N} w_{j} f\left(x_{j}\right)$. При цьому вагова функція поліному Якобі має вигляд $W(x)=(1-x)^{\alpha}(1+x)^{\beta}$, де $\alpha=\beta-$ коефіцієнти вагової функції поліному Якобі (за замовчуванням $0,5)$.

Оскільки ЧМІ Гауса-Якобі дає можливість отримати наближений розв'язок визначеного інтегралу на проміжку інтегрування $x \in[-1 ; 1]$ для функції $f(x)$, дуже часто в якості $f(x)$ розглядають розподіл швидкості потоку в перерізі ВТ. При цьому відомі тільки декілька швидкостей, виміряних у точках розташування АК УЗВ. Тобто, розглядаючи симетричний незбурений профіль швидкості потоку під час усталеного режиму руху потоку як вагову функцію $W(x)$ у вигляді $\left(1-x^{2}\right)^{k}$, де $k=\alpha=\beta$, зміною значень $k(k>0)[2,3]$, можна наблизити форму кривої $W(x)$, до вигляду кривої розподілу швидкості потоку у ВТ. При цьому буде отримано значення $x$ та $w$, які забезпечать якнайбільш точне інтегрування профілю швидкості, а отже і витрати потоку.

Для прикладу, у роботах [2, 3] авторами пропонується модифікація вагової функції полінома Якобі таким чином, щоб вона була аналітично близькою до функції розподілу швидкості (розподілу елементарної витрати потоку, area-flow-function). На основі цього підходу у [2] запропоновано вибрати коефіцієнт $k$ рівним 0,6 та розроблено новий ЧМІ під назвою OWICS (Optimal Weighted Integration for Circular Section). Для цього методу у [3] представлені аналітичні залежності для розрахунку абсцис та вагів ЧМІ в залежності від кількості $N$. Проте, досі не існує залежностей, які б охоплювали увесь діапазон $k$ для найбільш типової кількості АК УЗВ $N=2 \ldots 4$. Тому, в цій роботі розроблено такі аналітичні залежності, що зв'яжуть значення $x(i)$ та $w(i)$ зі значенням $k$ ЧМІ ГаусаЯкобі для $N=2 \ldots 4$ хордових УЗВ.

Розробка аналітичних залежностей для координат розташування АК УЗВ. Розрахунок координат розташування АК УЗВ може мати декілька реалізацій, як це показано в $[3,9,10]$. Оскільки поліном Якобі є табличним ортогональним поліномом [8], для якого відоме рекурентне рівняння (2), доцільним буде застосувати наступний алгоритм розробки аналітичних зеленостей для координат розташування АК УЗВ по аналогії знаходження абсцис ЧМІ Гауса-Якобі на основі якого він побудований:

1. Вибір значення $N$ з діапазону $N=2 \ldots 4$.

2. Вибір значення $k$ з діапазону $k=0,5 \ldots 0,9$.

3. Побудова рекурентних рівнянь поліному Якобі за модифікованою класичною формулою (2), в якій коефіцієнти $\alpha$ та $\beta$ замінені на $k$.

$$
\begin{aligned}
& p_{j+1}=\frac{\left(d_{j}+e_{j} x\right) p_{j}-f_{j} p_{j-1}}{c_{j}} ;(j=0,1, \ldots N-1) ; k>-1 \\
& c_{j}=2(j+1)(j+2 k+1) 2(j+k) \\
& d_{j}=2(j+k+0,5) \\
& e_{j}=2(j+k) 2(j+k+0,5) 2(j+k+1) \\
& f_{j}=2(j+k) 4 k(j+k+1) \\
& p_{-1}=0 ; \quad p_{0}=1
\end{aligned}
$$

4. Знаходження коренів поліному Якобі $p_{j+1}$, які й будуть абсцисами ЧМІ Гауса-Якобі, а відповідно $x(i)$ - координатами розташування АК УЗВ. Для знаходження коренів поліному Якобі в даній роботі використано функцію roots програмного середовища MATLAB. Результати розрахунку координат розташування АК УЗВ зведено в табл.1, де індекси біля $x$ - це номери АК УЗВ.

Таблиця 1. Координати розташування АК УЗВ за ЧМІ Гауса-Якобі

\begin{tabular}{|c|c|c|c|c|c|}
\hline \multirow{2}{*}{$k$} & $N=2$ & \multicolumn{2}{|c|}{$N=3$} & \multicolumn{2}{c|}{$N=4$} \\
\cline { 2 - 6 } & $x_{1,2}$ & $x_{1,3}$ & $x_{2}$ & $x_{1,4}$ & $x_{2,3}$ \\
\hline 0,50 & $\pm 0,5000$ & $\pm 0,7071$ & 0 & $\pm 0,8090$ & $\pm 0,3090$ \\
\hline 0,60 & $\pm 0,4880$ & $\pm 0,6956$ & 0 & $\pm 0,7996$ & $\pm 0,3038$ \\
\hline 0,70 & $\pm 0,4767$ & $\pm 0,6846$ & 0 & $\pm 0,7905$ & $\pm 0,2988$ \\
\hline
\end{tabular}

(C) Роман B.I., Іжик А.Б. 


\begin{tabular}{|l|l|l|l|l|l|}
\hline 0,80 & $\pm 0,4662$ & $\pm 0,6741$ & 0 & $\pm 0,7817$ & $\pm 0,2940$ \\
\hline 0,90 & $\pm 0,4564$ & $\pm 0,6642$ & 0 & $\pm 0,7732$ & $\pm 0,2895$ \\
\hline
\end{tabular}

5. Провівши аналіз отриманих результатів, шляхом апроксимації поліномами різного степеня, отримуємо наступні аналітичні залежності $x=\mathrm{f}(k)$ та середньоквадратичне відхилення (СКВ) по відношенню до табличних значень:

$$
\begin{array}{lll}
N=2: & x_{1,2}=0,0368 \cdot k^{2}-0,1604 \cdot k+0,571 & \left(\mathrm{CKB}=2,210 \cdot 10^{-5}\right) \\
N=3: & x_{1,3}=0,0251 \cdot k^{2}-0,1423 \cdot k+0,772 & \left(\mathrm{CKB}=1,997 \cdot 10^{-5}\right) \\
& x_{2}=0 & \\
N=4: & x_{1,4}=0,0146 \cdot k^{2}-0,1098 \cdot k+0,8602 & \left(\mathrm{CKB}=2,375 \cdot 10^{-5}\right) \\
& x_{2,3}=0,0115 \cdot k^{2}-0,0647 \cdot k+0,3385 & \left(\mathrm{CKB}=7,428 \cdot 10^{-6}\right)
\end{array}
$$

Графіки отриманих поліноміальних аналітичні залежності $x=\mathrm{f}(k)$ наведено на рис.2.
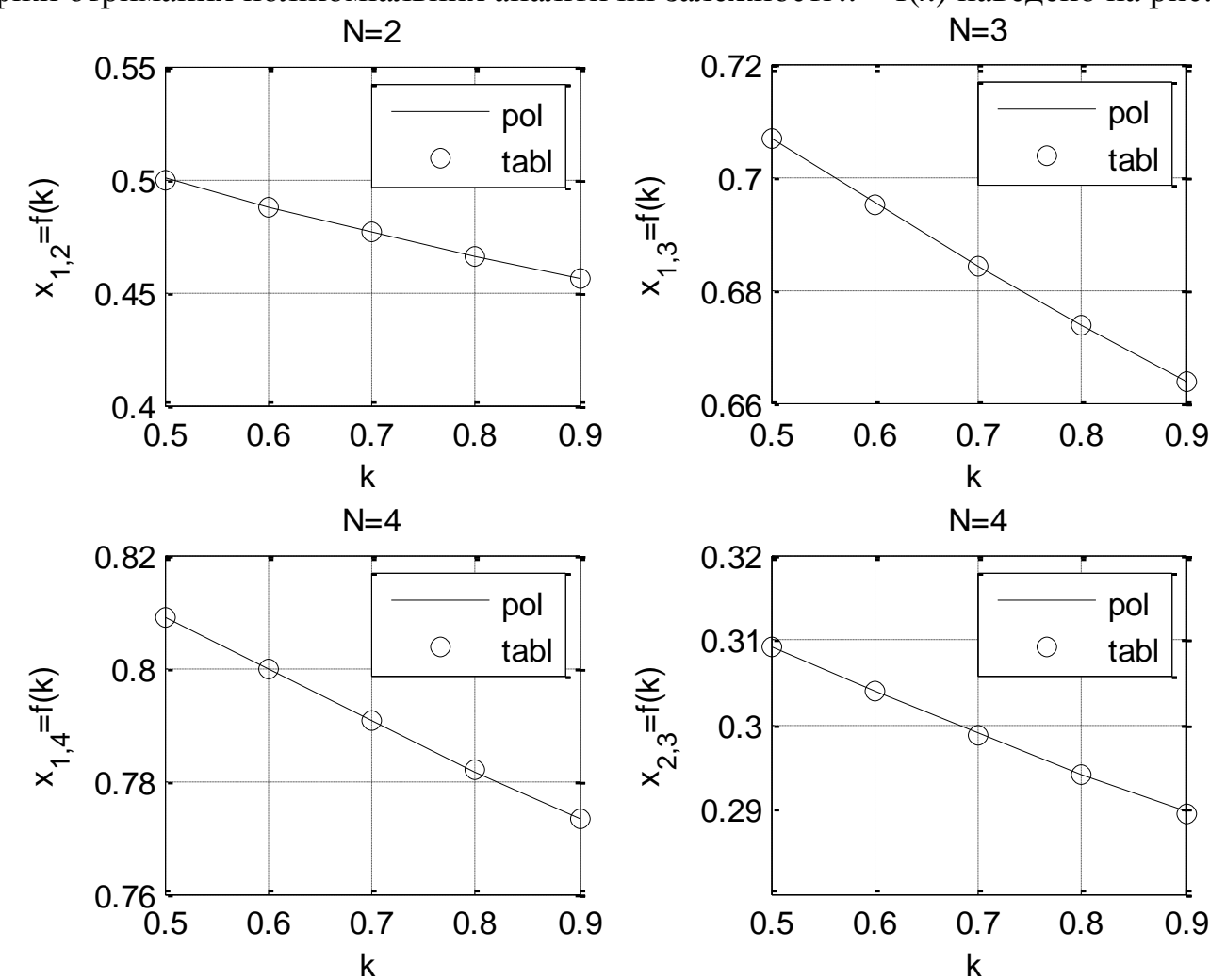

Рис.2. Графіки аналітичних залежностей $x=\mathrm{f}(k)$ для УЗВ з різним значенням $N$ : $p o l$ - крива за поліномом, $t a b l$ - табличні дані

Розробка аналітичних залежностей для вагових коефіціснтів АК УЗВ. Для більшості ЧМІ, які застосовуються для ультразвукової витратометрії, зокрема Гауса-Лежандра, Гауса-Чебишева 1-го порядку, Гауса-Чебишева 2-го порядку, науковцями отримані прості аналітичні залежності для визначення вагів $[8,9]$. Однак, для методу на основі ЧМІ Гауса-Якобі, визначення вагів (вагових коефіцієнтів АК УЗВ) відбувається за іншим підходом. Згідно $[8,9]$ розрахунок вагових коефіцієнтів АК на основі ЧМІ Гауса-Якобі може бути виконаний за наступною формулою виду $w(i)=\frac{1}{W(x(i))} \int_{a}^{b} W(x) P L_{i}(x) d x ;(i=1,2, \ldots N), \quad$ де $\quad P L_{i}(x) \quad-\quad$ поліном Лагранжа $P L_{i}(x)=\prod_{\substack{l=0 \\ l \neq j}}^{N} \frac{x-x(i)}{x(i)-x(l)}$

Підставляючи отримані вище значення координат розташування $x$ та значення $k$, для яких вони були отримані, розраховуємо вагові коефіцієнти $w$. Результати розрахунку вагових коефіцієнтів АК УЗВ зведено в табл.2.

(C) Роман B.I., Іжик А.Б. 
Таблиця 2. Вагові коефіцієнти АК УЗВ за ЧМІ Гауса-Якобі

\begin{tabular}{|c|c|c|c|c|c|}
\hline \multirow{2}{*}{$k$} & $N=2$ & \multicolumn{2}{|c|}{$N=3$} & \multicolumn{2}{c|}{$N=4$} \\
\cline { 2 - 6 } & $w_{1,2}$ & $w_{1,3}$ & $w_{2}$ & $w_{1,4}$ & $w_{2,3}$ \\
\hline 0,50 & 0,9069 & 0,5554 & 0,7853 & 0,3693 & 0,5976 \\
\hline 0,60 & 0,8908 & 0,5537 & 0,7687 & 0,3719 & 0,5882 \\
\hline 0,70 & 0,8754 & 0,5517 & 0,7530 & 0,3740 & 0,5793 \\
\hline 0,80 & 0,8607 & 0,5495 & 0,7382 & 0,3758 & 0,5708 \\
\hline 0,90 & 0,8467 & 0,5470 & 0,7242 & 0,3772 & 0,5626 \\
\hline
\end{tabular}

Провівши аналіз отриманих результатів, шляхом апроксимації поліномами другого степеня, отримуємо наступні аналітичні залежності $w=\mathrm{f}(k)$ :

$$
\begin{array}{lll}
N=2: & w_{1,2}=0,0349 \cdot k^{2}-0,1992 \cdot k+0,9978 & \left(\mathrm{CKB}=1,957 \cdot 10^{-5}\right) \\
N=3: & w_{1,3}=-0,013032 \cdot k^{2}-0,002628 \cdot k+0,55996 & \left(\mathrm{CKB}=1,904 \cdot 10^{-5}\right) \\
& w_{2}=0,047 \cdot k^{2}-0,2185 \cdot k+0,8828 & \left(\mathrm{CKB}=5,387 \cdot 10^{-5}\right) \\
N=4: & w_{1,4}=-0,0185 \cdot k^{2}+0,0457 \cdot k+0,351 & \left(\mathrm{CKB}=4,545 \cdot 10^{-5}\right) \\
& w_{2,3}=0,02 \cdot k^{2}-0,116 \cdot k+0,65 & \left(\mathrm{CKB}=5,061 \cdot 10^{-5}\right)
\end{array}
$$

Графіки отриманих поліноміальних аналітичні залежності $w=\mathrm{f}(k)$ наведено на рис.3.
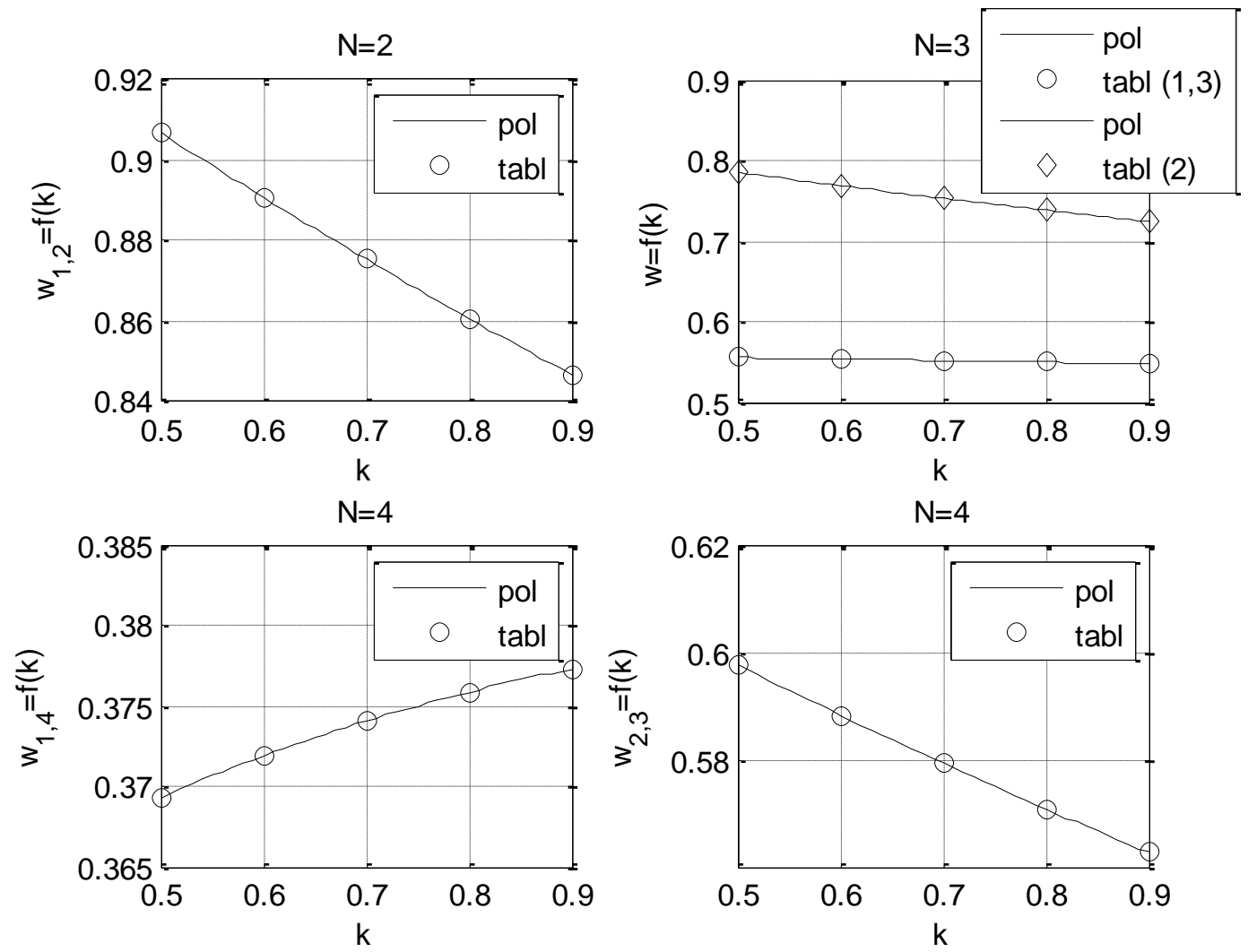

Рис.3. Графіки аналітичних залежностей $w=\mathrm{f}(k)$ для УЗВ з різним значенням $N$ : $p o l$ - крива за поліномом, tabl- табличні дані

Висновки та перспективи подальшого дослідження. За результатами виконаних досліджень, було вперше розроблено аналітичні залежності $x=\mathrm{f}(k)$ та $w=\mathrm{f}(k)$ для ЧМІ Гауса-Якобі $(N=2 \ldots 4)$. Всі залежності були описані поліномами другого порядку, що в подальшому дозволяє застосовувати їх для розрахунку складових рівняння об'ємної витрати багатоканальних хордових УЗВ $(x$ та $w)$ без застосування ітераційних процедур та довідкових таблиць даних ЧМІ Гауса-Якобі. Також, слід зазначити, що подібні залежності $x=\mathrm{f}(k)$ та $w=\mathrm{f}(k)$ для ЧМІ Гауса-Якобі можна легко (за необхідності) розробити для УЗВ з $N$ більше 4. Під перспективою подальших досліджень авторами вбачається застосування розроблених залежності $x=\mathrm{f}(k)$ та $w=\mathrm{f}(k)$ при пошуку шляхів усунення похибок УЗВ, зумовлених роботою витратомірів в умовах спотворень структури потоку - задача пошуку конструкції УЗВ інваріантної до гідродинамічних збурень потоку. 
Список бібліографічного опису

1. International Organization for Standardization. (2010). ISO 17089-1: Measurement of fluid flow in closed conduits - Ultrasonic meters for gas. Part 1: Meters for custody transfer and allocation measurement. Geneva, Switzerland: ISO.

2. Tresch, T., Gruber, P., \& Staubli, T. (2006, July 30 - August 1). Comparison of integration methods for multipath acoustic discharge measurements. Paper presented at the Proceedings of the 6th International Conference on IGHEM, Portland Oregon, USA. doi: http://www.ighem.org.

3. Voser, A. (1999). Analysis and error optimization of multipath strength acoustic flow measurement in water turbines. Unpublished master's doctoral dissertation, Swiss Federal Institute of Technology Zurich, Zurich, Switzerland.

4. Pannel, C. N., Evans, C. N., \& Jackson, D. A. (1990). A new integration technique for flowmeters with chordal paths. Flow Measurement Instrumentation, 1, 216-224.

5. Moore, P. I., Brown, G. J., \& Simpson, B. P. (2000). Ultrasonic transit- time flowmeters modeled with theoretical velocity profiles: methodology. Meas. Sci. Technol, 11, 1802-1811.

6. American Gas Association. (2007). AGA Transmission Measurement Committee Report No.9: Measurement of gas by multipath ultrasonic meters (2nd ed.). Washington, DC: AGA.

7. The European Gas Research Group. (2000). GERG Technical Monograph No.11: Project on Ultrasonic Gas Flow Meters, Phase II. Brussels, Belgium: GERG.

8. Abramovitz, M., \& Stegum, I. (1964). Handbook of mathematical function. New York, NY: NBS.

9. Press, W. H., Teukolsky S. A., Vetterling W. T., \& Flannery B. P. (1995). Numerical Recipes in C (2nd ed.). Cambridge, England: Cambridge University Press.

10. Терещенко С. А. Акустическая многоплоскостная расходометрия на основе методов квадратурного интегрирования / С. А. Терещенко, М. Н. Рычагов // Акустический журнал. - 2004. - Том 50, № 1. - С. 116-122.

11. Костылев В. В. Принципы построения многоканального ультразвукового расходомера / В. В. Костылев, В. Л. Сорокопут, А. А. Стеценко, А. И. Стеценко // Совершенствование измерений расхода жидкости, газа и пара : 12-та международная научно-практическая конференция, 23-25 апреля 2002 г. : тезисы докл. - СПб. : Борей-Арт, 2002. - С. 288.

13. Гаврилюк І. П. Методи обчислень. У 2 ч. Ч. 1: підручник / І. П. Гаврилюк, В. Л. Макаров. - К. : Вища школа, $1995 .-367$ c. - ISBN 5-11-00411102.

14. Остафійчук В.Я. (2020). Дослідження конструктивних характеристик ультразвукових витратомірів. Магістерська кваліфікаційна робота. Національний університет «Львівська політехніка», Львів. -74 с .

\section{References}

1. International Organization for Standardization. (2010). ISO 17089-1: Measurement of fluid flow in closed conduits - Ultrasonic meters for gas. Part 1: Meters for custody transfer and allocation measurement. Geneva, Switzerland: ISO.

2. Tresch, T., Gruber, P., \& Staubli, T. (2006, July 30 - August 1). Comparison of integration methods for multipath acoustic discharge measurements. Paper presented at the Proceedings of the 6th International Conference on IGHEM, Portland Oregon, USA.

3. Voser, A. (1999). Analysis and error optimization of multipath strength acoustic flow measurement in water turbines. Unpublished master's doctoral dissertation, Swiss Federal Institute of Technology Zurich, Zurich, Switzerland.

4. Pannel, C. N., Evans, C. N., \& Jackson, D. A. (1990). A new integration technique for flowmeters with chordal paths. Flow Measurement Instrumentation, 1, 216-224.

5. Moore, P. I., Brown, G. J., \& Simpson, B. P. (2000). Ultrasonic transit-time flowmeters modeled with theoretical velocity profiles: methodology. Meas. Sci. Technol, 11, 1802-1811.

6. American Gas Association. (2007). AGA Transmission Measurement Committee Report No.9: Measurement of gas by multipath ultrasonic meters (2nd ed.). Washington, DC: AGA.

7. The European Gas Research Group. (2000). GERG Technical Monograph No.11: Project on Ultrasonic Gas Flow Meters, Phase II. Brussels, Belgium: GERG.

8. Abramovitz, M., \& Stegum, I. (1964). Handbook of mathematical function. New York, NY: NBS.

9. Press, W. H., Teukolsky S. A., Vetterling W. T., \& Flannery B. P. (1995). Numerical Recipes in C (2nd ed.). Cambridge, England: Cambridge University Press.

10. Tereshchenko, S. A., \& Rychagov, M. N. (2004). Multiplane acoustic flowmetering based on quadrature integration methods. Acoustic magazine. 50(1), 116-122.

11. Kostylev, V. V., Sorokoput, V. L., Stecenko, A. A., \& Stecenko, A. I. (2002, April 23-25). Principles of construction of a multichannel ultrasonic flowmeter. Paper presented at the Proceedings of the $12^{\text {th }}$ international scientific and practical conference "Improvement of flow measurement of liquid, gas and steam", St. Petersburg.

13. Havrylyuk, I. P., \& Makarov, V. L. (1995). Methods of computation. In Part 2. Part 1. Tutorial. Kyiv: Vyshcha shkola.

14. Ostafiychuk V.Ya. (2020). Research of design characteristics of ultrasonic flowmeters. Master's thesis. Lviv Polytechnic National University, Lviv. - 74 pages. 